\title{
A RIVER THROUGH TIME
}

$\mathrm{T}$ This text is an account of my thoughts on the relationships between time, film and sound as an art practice throughout the making of my film Douro: Symphony of a river.

I initiated this journey as a sound recordist, as an appreciator of nature and the acoustic environment. Through the best part of a decade I actively engaged with a geographical path carved by the flow of water, trying to unravel its secrets, mysteries and any stories it could whisper in the quiet of the night or in a hot summer's afternoon. The river, the principal character of this work, had already started its journey many millennia before mine, spreading life throughout the Iberian Peninsula, and serving as a pathway which connected the first pre-historic settlements found across its banks, through to the present day, where its cultural importance largely transcends the political borders created by man throughout the centuries.

\section{FROM SOUND TO FILM}

My journey in the Douro river started with a collection of sounds, followed by an online sound map, through to published releases and presently into a documentary film.

Whilst listening attentively to the path of a river the observer is presented with a plenitude of sounds with different characteristics; these are either of natural or human origins, of different pitches and timbers, lengths, amplitudes and rhythms that when combined create an everchanging acoustic environment.

The soundscape (Schaffer 1994 [1977]: 274) also changes dramatically between seasons; from the seemingly quiet winter months, where time seems to stand still, through to early Spring where the melting of the snow, high up in the mountains, combines into small streams which fiercely descend 2000 meters to the valleys bellow. An exciting blanket of white noise involves everything around it, as a hyperamplified call to life, forecasting the dynamic Summer months that follow.

In such a changing acoustic environment, the most prominent sound mark (Schaffer 1994: 274) is the continuous drone created by the flow of the water. As the theme of a musical composition, it is from this element that all other sounds seem to emanate, and it would also serve as the structure, the sonic and visual path of the film.

In this manner sound informed the film, not the camera.

\section{DRONE, TIME AND RHYTHM}

Unlike other musical genres which are characterized by the organized intervals between sound and silence for its dynamic continuity, a musical drone is, to me, defined by its ability to evoke stillness, to refrain from the passage of time due to its seemingly uneventful progression. To be encapsulated in its grasp is to be cut from the outside in a continuous immersive experience which ultimately challenges the ephemerous qualities of sound.

My experience whilst recording the Douro led me to regard the river's sonic drone as more than a landscape's sound mark. Its constant enveloping presence can create an almost transcendental experience, an aural blanket which defies time and comforts in the silence of the night whilst recording in remote locations. 
Although the movie does not necessarily intend to present the river as a mystical journey, I find these ideas fascinating. The drone as a celebration of the continuity of life, and the flow of water as the main driving force of the film.

Through the manipulation of audio recordings captured along the river, I composed four electroacoustic pieces that adhere to these ideas and represent different stages of the river's path.

\section{ON THE PERCEPTION OF TIME}

I get the impression that the film starts quite slow and becomes more exciting and fast-paced as the last two sequences are introduced. This might be due to the perception of quietness associated with experiencing the natural environment, and from the stillness of the night in the film's second sequence. This contrasts with the sounds of heavy machinery and urban noise of the second part of the film, where, to me, the pace becomes faster, more dynamic, leading me to be more playful with the montage of the imagery. Time-lapse shots of Porto's urban life are guided to the rhythm of church bells, which resonate throughout the landscape at different times of the day, as a constant reminder of the passing of time.

Just as in any musical composition, the film is open to multiple interpretations. The lack of a driving voice leading the narrative invites the viewer to listen and engage with the film in his own tempo, through his own perception. This was certainly true in the various viewings of the film thus far, where the experience of the film's pace varied from spectator to spectator.

We experience time as a linear and continuous progression of events from which we cannot physically deviate, but we experience its unfolding individually. My experience of viewing 8 years of my life contained in 15' 22" seconds of film is quite intimidating perhaps, as I compare my transient life to the perpetuity of its main character, the Douro river.

\section{REFERENCES}

Schaffer, R. Murray 1994 [1977]. Our Sonic Environment and be Soundscape: The Tuning of the World. Rochester: Destiny Books.

VIRGILIO OLIVEIRA

UNIVERSITY OF THE ARTS LONDON

vddoliveira@hotmail.com 